\title{
Cognition and Communication in Architectural Design
}

Tenbrink, T.; Hoelscher, C.; Tsigaridi, D.; Conroy Dalton, R.; Montello, D.R.; Grossner, K.E.

\section{Space in Mind: Concepts for Spatial Learning and Education}

Published: 21/12/2014

Peer reviewed version

Cyswllt i'r cyhoeddiad / Link to publication

Dyfyniad o'r fersiwn a gyhoeddwyd / Citation for published version (APA):

Tenbrink, T., Hoelscher, C., Tsigaridi, D., Conroy Dalton, R., Montello, D. R. (Ed.), \& Grossner, K. E. (Ed.) (2014). Cognition and Communication in Architectural Design. In Space in Mind: Concepts for Spatial Learning and Education (pp. 263-280). MIT Press.

\footnotetext{
Hawliau Cyffredinol / General rights

Copyright and moral rights for the publications made accessible in the public portal are retained by the authors and/or other copyright owners and it is a condition of accessing publications that users recognise and abide by the legal requirements associated with these rights.

- Users may download and print one copy of any publication from the public portal for the purpose of private study or research.

- You may not further distribute the material or use it for any profit-making activity or commercial gain

- You may freely distribute the URL identifying the publication in the public portal ?
}

Take down policy

If you believe that this document breaches copyright please contact us providing details, and we will remove access to the work immediately and investigate your claim. 


\section{Cognition and Communication in Architectural Design}

Thora Tenbrink ${ }^{\mathrm{a}, \mathrm{b}}$, Christoph Hölscher ${ }^{\mathrm{b}, \mathrm{c}}$,

Dido Tsigaridid ${ }^{\mathrm{d}}$, and Ruth Conroy Dalton ${ }^{\mathrm{e}}$

a Bangor University, Wales, UK

b SFB/TR 8 Spatial Cognition,

Universities of Bremen/Freiburg, Germany

c ETH Zurich, Switzerland

d Harvard University, Boston, MA, USA

e Northumbria University, UK 
Abstract. During building design, architects communicate frequently with numerous stakeholders: primarily with their clients and occasionally with future building occupants. Each group is characterized by a different mindset concerning design issues, and each draws on a different conceptual background, leading to diverging terminology and potential miscommunication. In this paper, we discuss the challenges that arise due to the discrepant discourses and points of view employed by the people involved. The architect perspective involves complex considerations of aesthetics, innovation and creativity, functionality, and multiple other issues. The user perspective is more strongly focused on perception of the environment, functionality, appropriation, and wayfinding; and the client perspective may center on economical, functional, and aesthetic aspects. These different mindsets pose substantial challenges for the education of architects to adopt communication practices that are client oriented and user sensitive. 


\section{Introduction}

What, do you think, is a corner, and what might it be important for? Your answer will depend on who you are and what is relevant for you in a given discourse context. Even in the restricted context of buildings, corners can be associated with multiple concepts. Perceived from the outside, corners are typically convex and define the overall form of a building. From the inside, they are often concave, and represent semi-enclosed spaces formed by intersecting wallplanes. In each case, different levels of function and perception are revealed.

As such, convexity and concavity establish the status of a phenomenon's entity - they define where objects and regions begin and end, and are perceived at a high level of abstraction (Wang, 2011). Corners, in particular, play different roles for different people, depending on the level of granularity, vantage point, and context. Inside a building, a room's corner provides space to place furniture; a corner in a hallway may signal the existence of a turn, and thus obscure the view ahead. The interior of a corner can be used for shelter and provide a space for retreat, whereas the exterior of a corner might serve as an outlook point.

Architects typically determine the building's massing (its overall shape and size) based on its outside bounding edges, captured by diagrams outlining the formal composition of the external convex shape. These formal considerations are, at times, so heavily semantically loaded that they may lead to exceptional treatment of the building corners. Van der Rohe, one of the most influential modern architects of the past century, was obsessed with the detail of the corner; he offered design solutions on how to articulate this unique endpoint of the 
building so as to smoothly transition from one wall to the other (see, for example, the Crown Hall in the Illinois Institute of Technology campus). In the Cooper Union Foundation (2009), the architect, Mayne, takes the symbolic function of the corner to a different level. He curves the corner of the entire building block by lifting it up-a gesture meant to invite the passers-by into the interior lobby of the building.

While architects are preoccupied with formal, aesthetic, symbolic and functional considerations, clients (the people commissioning the architects) might be viewing buildings' corners quite differently. For a client, interior corners may be economically relevant, as they provide space to be used commercially. The act of "lifting" a corner of a building, for example, might be viewed by clients as a financial waste, due to lost usable space and increased construction costs. A building user's perception and appropriation of the corner space may still differ. Users (the people who will ultimately inhabit/visit/work in a building) may appreciate the aesthetic appearence of corners and their impact on the functionality of the building, but they may also perceive a corner as relevant for their personal building use. Given these discrepancies, encountering the word 'corner' may lead to different associations, to the point of referring to completely discrepant concepts. Consequently, communication about corners may require substantial elaboration and negotiation.

This chapter aims to shed light on these issues more systematically by addressing the diversity of conceptual perspectives involved in architectural design, focusing on the individual roles of the architect, user, and client. The need 
to interact and communicate so as to enable design solutions favored by all parties pose major challenges for everybody involved, and this has clear educational implications.

As in our example, architectural design generally involves various expectations, functions, and purposes, depending on the perspective adopted towards the design task. This already poses challenges for architects dealing with diverse demands - even without the need to communicate. Then in the discussion of particular aspects of a building between various stakeholders, the diversity of concepts may lead to communication problems that may increase if the discrepancy remains undetected. Unfortunately, neither graphic nor verbal language reflects the fundamental differences in perspectives in directly observable ways. Using our initial example, a corner may always be referred to as corner, independent of the actual concept at stake. While conceptual divergences between speakers may be subtle, and the language used may converge, people may still be talking at cross-purposes without necessarily being able to pinpoint any concrete discrepancies. They may not notice that they are actually engaging in diverging discourses, drawing on different background assumptions as well as pursuing different goals.

Adrian Forty (2000) dedicated a voluminous book to the relation between language and modern architecture, providing insights into an impressive range of concepts at the heart of architectural thinking-using words that may be associated with different, perhaps less rich, concepts by non-architects. For instance, the concept of flexibility in architecture touches upon issues of 
redundancy (creating margins for flexible usage), technical means (enabling flexible usage by installing moveable partitions), and political strategies (disturbing established social order). Non-architects, even if centrally involved with building and construction, would not necessarily associate these phenomena with the term flexibility; this conceptual leap involves a world of background knowledge and experience with a particular kind of discourse, or way of thinking.

As in this example, architecture theory can provide a range of important insights about architects' perspectives and procedural knowledge. Other disciplines play further roles in understanding architectural phenomena and processes. Cognitive linguistics sheds light on words, associations, and communication issues. Design cognition addresses mental representations and cognitive strategies during the design process, and spatial cognition addresses wayfinding and comprehension problems of users of complex public buildings. While our focus in this chapter is on the conceptual perspectives of individuals and the degree to which they can adopt other relevant perspectives and communicate successfully, the discourses employed by each of these disciplines and communities inform our understanding of the discrepancies we are aiming to capture. In the next section, we take a brief look at issues around language and concepts relevant for architecture.

\section{Language and thought}

Communication, in a very basic sense, means conveying and exchanging thoughts between different minds, typically using language as a medium. Language, both graphic and verbal, serves as a tool to represent meanings selected 
from the broad spectrum of knowledge, opinions, perspectives, associations, and ideas that each communicator has available. Like any other tool, language can be used in flexible ways, depending on the user's individual needs in a particular context. This can be easily demonstrated when considering the many different meanings of a simple word like 'Okay': This can be uttered with various stress and intonation patterns, and it can refer to ideas as varied as acknowledgement of perceiving an utterance, agreement with its content, starting a new topic or discourse or task, and other things depending on context. This flexibility does not necessarily lead to misunderstandings; typically, speakers manage to get their meanings across 'sufficiently for current purposes', even though they may misinterpret subtle elements of the intended communication (Clark, 1996). From a cognitive linguistic point of view, words do not actually transfer meaning in any deterministic way, but rather serve as access points to an intricate network of concepts within the speakers' minds (Evans, 2009). Thus, although we use words (or, by analogy, drawings) to convey meanings and typically agree on one or more basic senses of meaning, words are flexible enough to activate different sets of concepts, depending on an individual's mindset and conceptual background. With a sufficient amount of shared common ground, this is not a problem. However, problems can arise if the same (seemingly unambiguous) expressions are used by people who draw on substantially different background knowledge, perspectives, and interests, without realizing the impact that these differences may have on understanding a concept. 
Architecture is a domain where various people come together to communicate about a shared topic, yet diverge massively with respect to expertise, experience, discourse, task goals, roles, responsibilities, and expectations. Communication in building design relies heavily on graphic language; the interaction architects have with their clients begins with verbal communication (clients use words to express their desires) and continues with graphic explorations (words are transformed into drawings and images). This process introduces substantial ambiguity (Cuff \& Robertson, 1982).

Consider a discussion about a staircase to be built. Architects may view this as a central element for circulation as well as aesthetic design. A staircase connects building levels, but it can also be highly visible to visitors if it presents an open space-with associated opportunities for architectural representation. Clients may be concerned with practical considerations and constraints, such as financial limitations or functional requirements concerning access to specific parts of the building, or meeting local fire regulations. Building users will appreciate a welldesigned staircase, but they also aim to reach their goal without getting lost. Staircases can support wayfinding and orientation; if they are visually prominent and placed centrally, they serve as visual landmarks and provide easy access to each part of the building, ideally allowing for suitable inferences about unencountered parts of the building. With repeated usage, users of a building may gradually develop a sense of appropriation, which in the case of staircases may lead to a preference for a particular path-'their' staircase. 
Similar observations could be made for many other parts of the building. As such, expressions like corner and staircase are not necessarily ambiguous-or even if they are, this may not be a problem, because the context will typically disambiguate basic senses of a polysemous term. The issue at stake is that these terms (and corresponding drawings) will inevitably activate access to different sets of concepts and associations in the minds of the people involved. Typically, the associated concepts and considerations are not made explicit. Architects considering a staircase may take it for granted that they understand it in terms of circulation, solid and void relationships, and aesthetics, while their clients may be puzzled about some of these suggestions.

Moreover, it is typically hard even to agree on a clearly delimited basic meaning of a word. A staircase can certainly be understood as a set of steps-but how many steps need to be involved to talk about a staircase? How far can different sets of steps be separated before speakers start talking about multiple staircases? Given an average size of a step, how much can an individual step depart from this size before it is no longer referred to as being part of the same staircase? Similar considerations apply for many other building parts. Pillars, for instance, can gradually merge into walls; upstands become balustrades; alcoves need to be of a certain size (but what size?) to be conceived of as a space in their own right. All of this is relevant to Wang's (2011) notion of cognitive identity: A wide range of cultural, social, and individual factors determine the extent to which a phenomenon is perceived in terms of a specific significance. 
Considerations such as these are common in an architect's everyday life, and they also relate directly to cognitive linguistics research. While the meanings of words were previously understood as sets of features needing to be determined by lexicographers, researchers now agree that they are best described in terms of prototypes or abstract schemas that do not necessarily or directly fit any deterministic description (e.g., Rosch, Mervis, Gray, Johnson, \& Boyes-Braem, 1975). A word like bird, for instance, typically triggers the association of a common exemplar that speakers would encounter regularly in their own culture; in the United States this would be a robin. Birds deviating substantially from the features of a robin, such as penguins, would still be understood as birds, but they take longer to come to mind, and their features (e.g., of being unable to fly) would not be considered as decisive for birds.

Considering the elements of a building, we can assume that words such as corner, staircase, pillar, and balustrade are associated with a number of basic spatial features according to the speakers' cultural background. However, even if architects, clients, and users share the same culture, their conceptual background will differ substantially, as we have seen. Thus, it is not at all clear that the spatial features subconsciously associated with each of these words would be similar for them-and this may not be clear in an architectural design discussion until it is made explicit by some turn of the conversation that requires clarifying such subtle details.

\section{The cognition and communication triangle of architectural design}


To represent the complexity of mindsets involved in the architectural design process as illustrated in the previous section, consider the triangular cognition and communication system with the following three vertices shown in Figure 1:

a) The architects' cognition and design processes, their abstract functional concepts of design space, individual objectives, creativity and innovation;

b) The users' intuitions and needs concerning spatial appropriation, ease of wayfinding, as well as their perception and experience of the spatial setting as a whole; and

c) The clients' views on the architectural challenge, including economical, functional, and aesthetical considerations.

These three vertices of the triangle enclose DESIGN as a conceptual target in the center, to which each of the vertices is related in a different way. Moreover, the vertices are interconnected by edges symbolizing conceptual perspective-taking as well as communication and interaction between architects, users, and clients, respectively. All of these employ different kinds of discourses when it comes to discussing spatial experience and configurations.

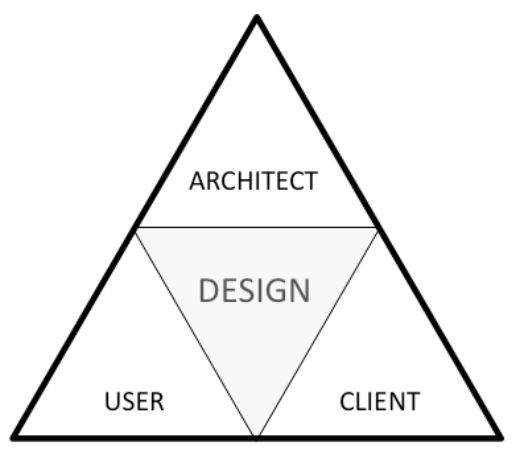

Figure 1. Cognitive agents involved in the architectural design process 
Let us take a closer look at the vertices and edges of this triangle. To set the stage, consider the key design phases as defined by The RIBA Plan of Work 2013,1 which provides a first impression of the uneven distribution of roles in the design process (which, in the triangle, is represented by the core of the system). In phase 0 'Strategic Definition', architects identify the core goals and requirements in communication with the clients. Phase 1 'Preparation and Brief' involves developing the project objectives and outcomes and defining constraints. These general goals are specified in further detail in each of the following phases to be carried out by the architects, called 'Concept Design', 'Developed Design', and 'Technical Design'. The actual 'Construction' phase is followed by 'Handover and Close Out', and concluded by a final phase called 'In Use'. In this process, clients are prominent in the initial design phase(s) by defining desired outcomes, requirements, and constraints; users do not emerge before the construction is completed. Nevertheless they may be implicitly present, as they will ultimately be evaluating the end product by either using it as intended by the clients, or encountering problems with it.

The triangle of key cognitive agents involved in the architectural design process shown above represents an abstraction of a range of possible configurations. In the case of the design of a complex public building, the triangle is simplified since roles need not be held by individuals. Architects and clients

\footnotetext{
${ }^{1}$ The design process described by the Royal Institute of British Architects (RIBA) and the one provided by the American Institute of Architects (AIA) share the same core stages. See http://www.architecture.com/Files/RIBAProfessionalServices/Practice/RIBAPlanofWork20130v erview.pdf and http://www.aia.org/aiaucmp/groups/aia/documents/pdf/aias077491.pdf (both accessed in October 2013).
} 
could be groups or teams, and users may be masses of people who do not know each other. Also, users may fall into different subgroups, sometimes called 'inhabitants' (permanent users) such as airport staff and teachers, and 'visitors' (temporary users) such as airline travellers and students. Typically, inhabitants will have fundamentally different ways of using a building than visitors, implying different perspectives on the design layout. Furthermore, subtasks of the design process such as the construction of documents involve further people with different backgrounds and perspectives on the process; this includes engineers, town planners, and experts on specific aspects of the building in question, such as energy or sustainability consultants.

In the case of private building design, the main roles of user and client may be represented by just one person. Then, both of these roles are relevant and may sometimes be in conflict with respect to their perspectives. As a user, the person will want to feel at ease in the building and appropriate it comfortably. As a client, the person will wish to focus on financial and other pragmatic constraints. While comfort and affordability need not be mutually exclusive, their combination often poses a challenge to be addressed by the skilled architect-notably based on communication with the person holding the dual role of client-and-user.

Depending on circumstances, there may be further people involved whose roles fall between the three main roles, so as to support and facilitate communication between them. In the case of complex buildings, a client advisor may provide a link between client and architect (cf. www.architecture.com), and a facility manager typically operates between client and user. A link between 
architects and users is sometimes facilitated through the process of participatory design. Thus, not only the vertices but also each of the edges of the triangle may be elaborated and enhanced in various ways (see Figure 2 below for the more complex case). The fact that established links exist between the different roles highlights the importance of reconciling the diverse conceptual perspectives involved.

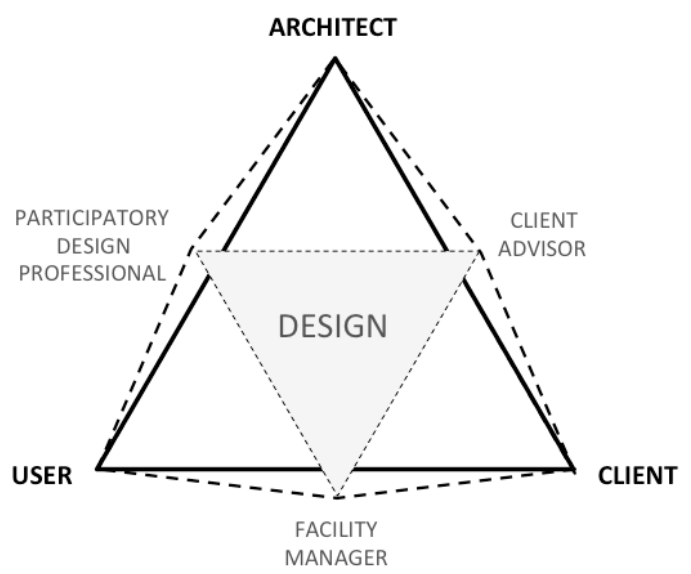

Figure 2. Negotiated vertices.

Taking an abstract view on the three vertices of the triangle, the architects are the experts in charge of the design process and play the most prominent role. The clients are also experts; some design issues cannot be resolved without them. Users seem to play the weakest role; they are not experts but 'naive' participants, and they rarely have a say throughout the design process. However, at least in the case of complex public buildings, while there can be architect teams and client companies consisting of more than one person, the number of people using the building will far exceed the number of experts involved in planning the building. Following construction, they will be the ones most involved with the building. 
Arguably, therefore, their role is the most important of the three. In the following, we will take a closer look at the user perspective on complex buildings before considering the clients' and architects' views, and the extent to which they take the user perspective into account.

\section{The user perspective}

People visit and inhabit publicly accessible buildings for any number of purposes, largely depending on a building's functions, be it a transport terminal, hospital, conference center or office space. A common requirement is that building users need to be able to find their way through the building. From a cognitive science perspective this is addressed in terms of navigation and wayfinding issues (Montello, 2005), based on a range of cognitive functions and subtasks, including locomotion, orientation, path planning, spatial reasoning, and spatial memory. Especially first-time visitors have little knowledge about a specific building, and therefore have to rely on cues from the environment for route planning and route following (for a taxonomy of different navigation tasks, see Wiener, Büchner \& Hölscher, 2009).

Users experience a building in a sequential fashion while moving through it, viewing the building from an egocentric perspective, perhaps guided by signs. While this process may be further supported by wall-mounted maps giving an overview of the building structure, this experiential perspective differs fundamentally from the allocentric perspective of floor plans and elevations primarily adopted by architects (Le Corbusier, 1931; Werner \& Long, 2003). 
Navigational success is obviously affected to a high extent by efficient and intuitive signage (Arthur \& Passini, 1992). Beyond signs and maps, ease of wayfinding is influenced both by building structure and by factors of human cognition (Carlson, Hölscher, Shipley, \& Conroy Dalton, 2010). With respect to building structure, wayfinding is affected mostly by factors such as the overall complexity of the corridor and room layout, the degree of visual distinctiveness of places, and visual access between decision points (Weisman, 1981). Here, spatial features like the corners discussed above become elements of the wayfinding process. While finding their way and making navigation decisions, building users often strive to understand the logic and structure of a building. This process incorporates perceptual cues of geometry such as lines of sight and the number of local movement choices (Haq \& Zimring, 2003; Wiener, Hölscher, Büchner, \& Konieczny, 2012), as well as semantically rich aspects like wall materials, textures, lighting and width of hallways, plus meaningful landmark objects that serve as cues to the destination (Frankenstein, Brüssow, Ruzzoli, \& Hölscher, 2012).

Since building users necessarily start by orienting towards local features sequentially as they experience them, developing a comprehensive cognitive map of a complex building can take a long time, depending on the extent to which a building is actually used in its entirety. For some people this inherently complex cognitive task is more challenging than for others, as humans differ in their spatial abilities and navigational styles (Wolbers \& Hegarty, 2010). Research in this area has identified a range of wayfinding strategies adopted by individuals, such as orienting primarily towards better-known central parts of a building (Golledge \& 
Spector, 1978), or attempting to find short-cuts between floors (Hölscher, Meilinger, Vrachliotis, Brösamle, \& Knauff, 2006). The route-choice strategies of a particular user develop over time and may change with familiarity with a building. Such changes in movement range and route choice are indicators of the user's appropriation of the building.

\section{The client perspective}

Clients may be represented by an individual person (and in the simplest case, may also be the end user as well, as described above), or they may be a group or board of a large institution, for example, a multinational company. In either case, one of the primary requirements of clients is to ensure that the resulting design represents value for money and that any concomitant risks (particularly financial ones) are minimized. As well as concerns about the initial investment, the next immediate and general concern is that the building should be 'fit for purpose'. These basic or expected needs of clients are represented in the classic project management triangle (Atkinson, 1999) in terms of the differing requirements for the money/time/quality triad of constraints of the construction project. Beyond the expected concerns that most clients might have of any construction project (i.e., scope, cost, time, risk and quality), there may be articulated or demanded needs, especially with respect to their expectations of how the end users of the building might behave in, use, or interact with the space.

The ways in which clients foresee a building being used will depend strongly on the building type, and therefore such aspects of the design will play a greater or lesser role according to type. One example where specific user- 
expectations of clients might become a specified need (i.e., articulated as such in the design brief) is in the design of an airport, where the clients may have clear and well-defined expectations of how building users will be guided through the building: efficiently and, where appropriate, separated into different types of user (departing and arriving travellers, for example). For the design of a shopping mall, the expectations of the clients could be quite different: Rather than moving through the building rapidly, the clients might wish to ensure that the chance of a shopper entering specific 'anchor stores' is high, that certain routes (where high 'footfall' is required) are prioritized and that, generally, people linger as long as possible (hence increasing the likelihood of making purchases). A third example might be the design of an office environment, where clients wish to promote a strong collaborative culture amongst employees, facilitated by fluid, barrier-free movement throughout the whole office environment. However, as Kamara, Anumba, and Evbuomwan (2002) point out, "[t]he business need underpinning the decision to commission a project can also conflict with the wishes and perspectives of other components within the client body. For example, a corporate decision to rationalise space through open-plan offices might conflict with the users' need for privacy" (p. 4). Therefore, despite the clients' apparent disposition to take into account the needs of the users via the building design brief, there may arise situations where the two sets of needs (the clients' and the users') are in conflict, or where the clients' perception of the user perspective does not correspond to the users' actual views.

\section{The architect Perspective}


The design process can be viewed as consisting of a series of tasks involving analytical tasks, acts of synthesis, and evaluation. These different tasks are frequently cyclical and will be interspersed with decision-making events.

Whether the task is to design a small bathroom or an entire city block, designers begin their work with the client and the design brief, an early statement of goals to be met. Analysis and research follow, and brainstorming sessions allow for the generation of early ideas and design solutions. Sketches, diagrams, and simple drawings visually assist the conceptualization of these solutions. These help architects in the definition of their aesthetic vocabulary, their problem solving processes and complex manifestations of visual thinking. It is over early drawings that the architect develops a personal conversation: Ideas form sketches, and sketches help form new ideas. Representational tools assist architects in the translation of abstract ideas into concrete design solutions. In graphically communicating their proposals, both among team members and to the clients, architects gradually move from explorative ideas (also known as the solution space) to the precise definition of the building and the finalization of schematic design. Design decisions made by the architects during this transition restrict the solution space; input or feedback given by other architects or the clients result in re-expanding, redefining, or further narrowing the solution space. The more aligned the perspectives of architects and clients are, the faster they can reach a design solution and move to design development; the more diverging their views are, the more times the architects will have to re-expand the solution space and propose new schematic designs. 
Notably, with the exception of the client being also the user, architects rarely receive input in their design solutions from the users. Also in relation to the client, nothing guarantees the establishment of successful communication. In fact, cases of exceptional architect-client communication are rather few. Among those, one of the most notable is the close collaboration of the famous Dutch architect Gerrit Rietveld with his client, Truus Schröder, for the design of the Schröder house (Friedman, 2007); Schröder held the roles of client and user. The degree to which her needs were accommodated by Rietveld is magnificently captured by numerous thoughtful house details - from the elegant mail slot of the front door to the small shelf for her eye-glasses, carefully positioned at hand's reach from her bedside. The Schröder story is a bright exception. Most often, architects' ideas are guided by their own ideals and beliefs, previous experience, personal desires and aesthetic preferences, and common-sense judgements.

As such, the creative process remains obscure and, in Glaser's (1996) words, it is rather "esoteric, highly specialized, full of internal rituals, and hard to understand from the outside." This process led Banham (1990) to call architecture a "black box" which would be "at the risk of destroying itself as an art in the process", if it were to be "opened up to the understandings of the profane and the vulgar".

Within this complex, cyclical and self-reflective process, how do architects conceptualize the role of the user? In the introduction to his book on the relationship between the architect and the building user, Till (2009) suggests that many architects view the user as being little more than a contaminant corrupting 
their pure environment: the unadulterated end-product of the complex design process described above. Part of the evidence for Till's view is the frequent absence of building users in architectural photography. This extreme view is, however, one that would be vehemently denied by many practicing architects who do profess to put building-users at the heart of their design endeavors. Clearly, there is a broad spectrum of attitudes, ranging from architects committed to participatory design (design processes that actively involve the end user in early stages of the design) to those who could be stigmatized as being dismissive of the end user, as Till suggests. It seems reasonable to assume that most architects are somewhere in the middle of this spectrum: They would like to think that they take the users' wishes and needs into account (and would take offense to the suggestion that they regard them as mere contaminants) but probably would not go as far as to involve end-users directly in the design process. Indeed, it simply "may not be possible to include most perspectives, particularly that of users, in the decision-making process" (Kamara et al., 2002).

Instead of direct consultation, architects frequently try to put themselves into the shoes of the user in order to understand what would be the users' experience of being inside and moving around the completed project. With respect to many experiences inside a yet-to-be-realized building, this approach is probably 'good enough' most of the time. For example, Peponis, Zimring, and Choi (1990) point out that architects use specific design features to support wayfinding, without assuming a 'one-shot' approach that works in all building settings. They give the example of including a central atrium, which can help convey a sense of 
the building's structure as well as offer direct visual access to other floors. Staircases and elevators that are strategically connected to the atrium provide support for orientation and efficient movement decisions.

Particularly during a complex design process, architects may adopt different perspectives depending on relevance at different stages (Tenbrink, Brösamle, and Hölscher, 2012). Conceptual shifts between perspectives may come along with systematic, perhaps subtle, shifts of the language used to refer to the same spatial phenomena. Thus, language use reflects how thoughts adopt new directions, highlighting the diversity of perspectives as well as the impracticality (or impossibility) of considering all of these in parallel.

A major obstacle for architects when imagining the user perspective lies in the fact that the majority of building users (and especially first-time visitors) have only partial or incomplete knowledge of the building that they are walking around in. This is in direct contrast to the architects, who have an almost 'godlike' omniscience with respect to the building (since it is the product of their own imagination and creativity). This makes it difficult for them to disregard their expert knowledge in order to take on the role of the naïve building user. It is generally challenging to estimate other people's knowledge and adapt communication styles accordingly (Bromme, Rambow, \& Nückles, 2001). For example, architects were found to severely overestimate knowledge of contemporary architecture in non-experts (Rambow, 2000), related to the specific ways in which everyday concepts and names are used in the architectural domain (Forty, 2000). 
The Seattle Public Library is a good example of a building where fundamental discrepancies have arisen between building users and architectural thinking. The architecture team, led by star architects Rem Koolhaas and Joshua Prince-Ramus (Kubo \& Prat, 2005), provided strong cues for navigating the building's ten stories, most prominently via brightly colored escalators. Unfortunately, these cues are only valid for navigating to a subset of the floors, while other destinations need to be accessed via less readily available routes. As a result, the building users sometimes need to resist the attraction of obvious route choices in order to choose the correct access to important locations and even entire floors (Carlson et al., 2010). While Koolhaas and colleagues clearly considered the users' behavior and tried to anticipate their intentions, actual behavior observation in the Seattle Public Library revealed serious wayfinding challenges for library patrons.

\section{Educational Implications}

Clearly, as we have shown, communication between architects, clients, and users may be problematic. What can be done to mitigate it? Initiatives such as the RIBA 'best client' awards and public outreach programs aiming to educate the public about architecture (http://www.londonopenhouse.org/) go some way to encourage dialogue between architects and their clients and users. Arguably, however, the easiest group to reach are the architects themselves, since enhancement of communication and mutual understanding could form part of their standard, architectural education. Some scholars have observed the lack of empathy architects show for human real-world needs, and the fact that, in the way 
architecture is being taught, it rather distances architects from serving people (Bandini, 1997).

Architectural education promotes experimentation with form, new materials, technologies, innovative representation and simulation techniques. What often escape architecture curricula are strategies to enhance students' sensitivity toward human issues (Thakur, 2006) - pedagogical methods for better understanding and communicating with clients and users. Architectural work is too permanent and too complex, one might argue, to accommodate everyone's desires. Nevertheless, this observation is not sufficient to justify why architects are so dismissive of well-established methods available for addressing people's needs, while embracing case-based learning, almost exclusively (Wright, 1996, Akin, 2002). The potential of other educational methods certainly needs to be explored.

One method that is currently being pioneered is to translate spatial cognition research into architecture education. The challenge is basically one of helping architects 'put themselves into the shoes' (perspective-taking) of their client or user. One method occasionally used in architecture schools is to confront students with a 'real client' (essentially a person who 'acts' as a client, even though the scenario may be fictitious) whom they can interview to gain insights into their requirements. Another method is to provide a rich and detailed description of an idealised user, similar to the concept of a 'persona' in product design/HCI. It clearly helps architects to put themselves into the shoes of their user, if they have a clear concept of who their user might be. 
Another approach is to encourage architects to observe the ways in which people use and inhabit the built environment on an everyday basis (pioneered by Gehl, 1971, and Whyte, 1980). In-depth ethnographic research can significantly inform design decisions, or even help shape the design brief. If we augment this approach with input from spatial cognition research, we can move from simple behavioural observations to teaching architects how to conduct cognitive walkthroughs: to 'role play' a user, performing a simple task in a real environment and noting assumptions made and problems encountered whilst performing it. Cognitive walkthroughs can serve both as ideation means and validation techniques. This can easily be combined with visits to real environments or buildings where users are already known to have navigational or wayfinding problems. As well as such 'direct experience' type exercises, these can be additionally supported or augmented with more traditional lectures and hands-on (paper-based) analytic exercises.

Finally, at the end of the design phase, when students typically present their design to their peers and tutors for assessment, the client/user perspective can be reintroduced and integrated into the traditional design 'crit'. This may be achieved by undertaking cognitive walkthroughs in virtual simulations of the building, by asking 'naive' users (not the student) to undertake simple explorative tasks in the building and to verbally feedback impressions, assumptions or difficulties. This approach is fairly new, as it requires a relatively sophisticated virtual reality provision; it was put to good use in a recent experimental educational program (Schneider et al., 2013). 


\section{Conclusion}

Starting from general observations about the role of cognition and conceptual perspectives in communication, we have discussed a cognition and communication triangle representing the architectural design process. By clarifying the different perspectives of people involved in this process, we have highlighted the fundamental conceptual discrepancies that need to be overcome for successful communication to be achieved. While the triangle shows equal vertices, the situation is further complicated in that each role can be filled in many different ways. Also, their relative importance is not equal, and neither are the edges of the triangle: Arguably there is no actual need for users to understand the architect perspective to the same extent as vice versa; the architects' purpose of designing a building towards future use and appropriation seems to be thwarted in a fundamental sense by a lack of understanding of the user perspective.

A number of promising (though largely unconnected) steps towards supportive intervention have been taken, such as establishing clear roles for client advisers and using participatory design methods. Given the rich empirical and theoretical background gained across relevant disciplines, such as cognitive science, cognitive linguistics, and design cognition, we suggest that the time is ripe for a more fundamental integration of insights in architectural training and design processes, along the lines suggested in our final section. Conceivably this will provide a further step towards the ultimate aim of architectural design: to 
incorporate the dreams of individuals across all three roles-architects, clients, and users, along with their diverse concepts and ideals. 


\section{References}

Akin, Ö. (2002). Case-based instruction strategies in architecture. Design Studies, $23,407-431$

Arthur, P., \& Passini, R. (1992). Wayfinding: People, signs, and architecture. Toronto: McGraw-Hill Book Co.

Atkinson, R. (1999). Project management: cost, time and quality, two best guesses and a phenomenon, its time to accept other success criteria. International Journal of Project Management, 17(6), 337-342.

Bandini, M. (1997). The conditions of criticism. In M. Pollak (Ed.), The Education of the Architect: Historiography, Urbanism, and the Growth of Architectural Knowledge. Cambridge, MA: The MIT Press, pp. 425-437.

Banham, R. (1990). A black box: The secret profession of Architecture. New Statesman \& Society, 12 (October), 22-25.

Bromme, R., Rambow, R., \& Nückles, M. (2001). Expertise and estimating what other people know: the influence of professional experience and type of knowledge. Journal of Experimental Psychology: Applied, 7(4), 317-30.

Carlson, L,. Hölscher, C., Shipley, T., \& Conroy Dalton, R. (2010). Getting lost in buildings. Current Directions in Psychological Science, 19(5), 284-289.

Clark, H. H. (1996). Using language. Cambridge: Cambridge University Press.

Cuff, D., \& Robertson, E. (1982). Words and Images: The Alchemy of Communication. Journal of Architectural Education, 36, 28-15.

Evans, V. (2009). How words mean: Lexical concepts, cognitive models and meaning construction. Oxford: Oxford University Press. 
Forty, A. (2000). Words and buildings: A vocabulary of modern architecture. London: Thames \& Hudson.

Frankenstein, J., Brüssow, S., Ruzzoli, F., \& Hölscher, C. (2012). The language of landmarks: The role of background knowledge in indoor wayfinding. Cognitive Processing, 13(1), 165-170.

Friedman, A. (2007). Women and the Making of the Modern House. Yale University Press.

Gehl, J. (1971). Life Between Buildings: Using Public Space. Washington: Island Press.

Glaser, M. (1996). Design and business: The war is over. AIGA Journal of Graphic Design, 14(3), 45-46.

Golledge, R. G., \& Spector, A. (1978). Comprehending the urban environment: Theory and practice. Geographical Analysis, 10, 403-426.

Haq, S., \& Zimring, C. (2003). Just down the road a piece: The development of topological knowledge of building layouts. Environment and Behavior, 35, $132-160$.

Hölscher, C., Meilinger, T., Vrachliotis, G., Brösamle, M., \& Knauff, M. (2006). Up the down staircase: Wayfinding strategies and multi-level buildings. Journal of Environmental Psychology, 26(4), 284-299.

Kamara, J. M., Anumba, C. J., \& Evbuomwan, N. F. (2002). Capturing client requirements in construction projects. London: ICE Publishing

Kubo, M., \& Prat, R. (2005). Seattle Public Library: OMA - Rem Koolhaas. Barcelona: Actar. 
Le Corbusier (1931/1986). Towards a new architecture. New York: Dover.

Montello, D. R. (2005). Navigation. In P. Shah \& A. Miyake (Eds.), The Cambridge handbook of visuospatial thinking (pp. 257-294). Cambridge: Cambridge University Press.

Peponis, J., Zimring, C., \& Choi, Y. K. (1990). Finding the building in wayfinding. Environment and Behavior, 22(5), 555-590.

Rambow, R. (2000). Experten-Laien-Kommunikation in der Architektur [Expert layperson communication in architecture]. Münster, Germany: Waxmann. Rosch, E., Mervis, C. B., Gray, W., Johnson, D., \& Boyes-Braem, P. (1975). Basic objects in natural categories. Cognitive Psychology, 8(3), 382-439.

Schneider, S., Kuliga, S., Hölscher, C., Conroy Dalton, R., Kunert, A., Kulik, A. and Donath, D. (2013) Educating architecture students to design buildings from the inside out - Experiences from an research-based design studio. 9th International Symposium, Seoul, South Korea.

Tenbrink, T., Brösamle, M., \& Hölscher, C. (2012). Flexibility of perspectives in architects' thinking. In C. Hölscher \& M. Bhatt (eds.), Proceedings of SCAD Spatial Cognition for Architectural Design, November 16-19, 2011, New York, USA. Report No. 029-08/2012 SFB/TR 8 Spatial Cognition, pp. 215-223. Thakur, A.B. (2006). Architecture Pedagogy: Psychological, Social, and Other Emergent Issues in the Design Studio. Electronic Theses, Treatises and Dissertations. Paper 1607. http://diginole.lib.fsu.edu/etd/1607 Till, J. (2009). Architecture depends. Cambridge, MA: The MIT Press. 
Wang, W. (2011). On the Notions of Cognitive Entities and Cognitive Identities in Architecture. Keynote lecture at Spatial Cognition for Architectural Design Symposium, New York, Nov 17, 2011.

Weisman, J. (1981). Evaluating architectural legibility: Wayfinding in the built environment. Environment \& Behavior, 13(2), 189-204.

Werner, S., \& Long, P. (2003). Cognition meets Le Corbusier-Cognitive principles of architectural design. In C. Freksa, W. Brauer, C. Habel, \& K. F. Wender (Eds.), Spatial cognition III (pp. 112-126). Heidelberg: Springer.

Whyte, W. H. (1980). The Social Life of Small Urban Spaces. Washington: Conservation Foundation

Wiener, J. M., Büchner, S. J., \& Hölscher, C. (2009). Taxonomy of human wayfinding tasks: A knowledge-based approach. Spatial Cognition and Computation, 9, $152-165$.

Wiener, J. M., Hölscher, C., Büchner, S., \& Konieczny, L. (2012). Gaze behaviour during space perception and spatial decision making. Psychological Research, 76(6), 713-729.

Wolbers, T., \& Hegarty, M. (2010) What determines our navigational abilities? Trends in Cognitive Sciences, 14, 138-146.

Wright, S. (1996). Case-based instruction: Linking theory to practice. Physical Educator, 53(4), 190-197. 